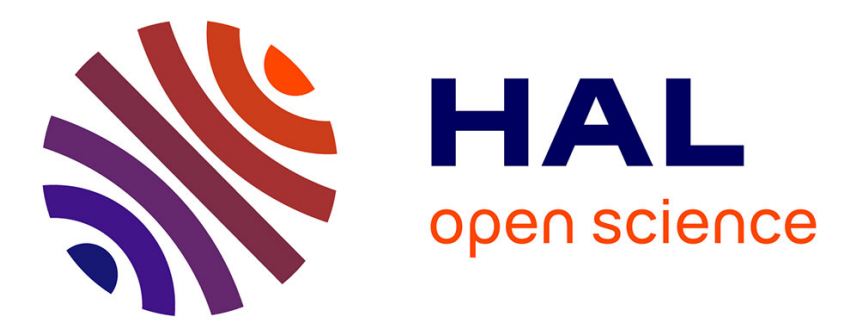

\title{
Mapping of proteomic profile and effect of the spongy layer in the human amniotic membrane
}

Parvin Nazari Hashemi, Fanny Chaventre, Aurelie Bisson, Julie Gueudry, Olivier Boyer, Marc Muraine

\section{- To cite this version:}

Parvin Nazari Hashemi, Fanny Chaventre, Aurelie Bisson, Julie Gueudry, Olivier Boyer, et al.. Mapping of proteomic profile and effect of the spongy layer in the human amniotic membrane. Cell and Tissue Banking, 2020, 21 (2), pp.329-338. 10.1007/s10561-020-09821-8 . hal-02955676

HAL Id: hal-02955676

https://hal-normandie-univ.archives-ouvertes.fr/hal-02955676

Submitted on 5 Oct 2020

HAL is a multi-disciplinary open access archive for the deposit and dissemination of scientific research documents, whether they are published or not. The documents may come from teaching and research institutions in France or abroad, or from public or private research centers.
L'archive ouverte pluridisciplinaire HAL, est destinée au dépôt et à la diffusion de documents scientifiques de niveau recherche, publiés ou non, émanant des établissements d'enseignement et de recherche français ou étrangers, des laboratoires publics ou privés. 


\title{
Mapping of proteomic profile and effect of the spongy layer in the human amniotic membrane
}

\author{
Parvin Nazari Hashemi · Fanny Chaventre · Aurelie Bisson · Julie Gueudry • \\ Olivier Boyer $\cdot$ Marc Muraine
}

Received: 15 November 2019/Revised: 27 February 2020/Accepted: 2 March 2020/Published online: 12 March 2020

\begin{abstract}
The graft of human amniotic membrane (HAM) contributes to the healing of corneal perforating ulcers and so to save a large number of eyes suffering of severe chemical burns. This biological material is used for the treatment of ocular surface diseases because of its capacity to reduce inflammation and promote a quicker wound healing. For clinical use, the HAM is denuded from its spongy layer, but this layer can be an important source of growth factors which promote re-epithelialization. The aim of our study is to provide a general view of protein expression of the HAM and the spongy layer and therefore to
\end{abstract}

Electronic supplementary material The online version of this article (https://doi.org/10.1007/s10561-020-09821-8) contains supplementary material, which is available to authorized users.

P. Nazari Hashemi $(\bowtie) \cdot$ O. Boyer · M. Muraine Faculty of Medicine and Pharmacy, University of Rouen Normandy, Inserm U1234, Rouen, France

e-mail: parvin-sadat.nazari-hashemi@etu.univ-rouen.fr

F. Chaventre - M. Muraine

Eye Bank of Normandy, Charles Nicolle Hospital, Rouen, France

\author{
A. Bisson - O. Boyer \\ Laboratory of Immunology and Biotherapy, Rouen \\ University Hospital, Rouen, France \\ J. Gueudry · M. Muraine \\ Department of Ophthalmology, Charles Nicolle Hospital, \\ Rouen University Hospital, Rouen, France
}

determine if the spongy layer and/or a specific part of HAM have a beneficial role in the process of wound healing in patients with corneal ulcers. For this study, human placentas were obtained from healthy women after vaginal delivery or caesarean section after signing the consent form. Mapping of protein expression is done by dividing the placenta in 2 equal parts, one with spongy layer and another without (conventional HAM). Each part is also divided in 3 zones depending on the distance from the umbilical cord. The proteomic analysis was done by ELISA, targeting growth factors (EGF, HGF, KGF, NGF and TGFbeta1) and pro inflammatory cytokine TNF- $\alpha$ in the HAM without spongy layer and in the spongy layer. In this study we observed significant difference in the total amount of protein extract between the different donors. We do not observe a significant difference in the growth factor level between the conventional HAM and the spongy layer. No variation was observed in the expression of HGF, KGF and NGF in different zone of HAM and neither between conventional HAM and spongy layer in each zone. $\left({ }^{*} p\right.$ value $<0.05$, $* * p$ value $<0.01,{ }^{* * *} p$ value $\left.<0.001\right)$. We do detect very low dose of TNF- $\alpha$ and no correlation with the amount of growth factors. In our study we demonstrated that keeping the spongy layer in conventional method of handling HAM can add more GF, and so probably have a positive affect the wound healing process. Variation in some growth factors expression has been observed between the placentas and therefore this may explain the variation in clinical results. No 
indicator for the selection of placentas with a higher rate of growth factor was found.

Keywords Amniotic membrane $\cdot$ Mapping · Growth factor · Spongy layer

\section{Introduction}

The Human Amniotic Membrane (HAM) is the inner layer of the placenta, which surround the fetus and is in contact with the amniotic liquid. The use of this biological material has been reported for the first time in ophthalmology by Rötth in 1940 for conjunctival defect and has been used widely for the treatment of corneal ulcer since 1995 (Rötth 1940; Kim and Tseng 1995). This biological material has anti-inflammatory and antiangiogenic properties by expressing molecules like IL10 and Thrombospondin-1 (Hao et al. 2000). Its basal membrane composed of collagen III, IV, V and VI, fibronectin and laminin plays a role as matrix for cell growth (Schmidt 1992; Malak et al. 1993; Parry and Strauss 1998). The presence of growth factors like EGF, HGF, KGF, NGF and TGF beta1 in HAM, which plays an important role in promoting of cell growth and proliferation in the process of wound healing, is the other interesting feature of use HAM in the process of wound healing (Koizumi et al. 2000). TGF beta plays a regulatory role in tight junction expression, HGF activates the proliferation of epithelial cells (Pierucci-Alves et al. 2012; Miyagi et al. 2018). NGF accelerates the process of wound healing by binding to its receptor TrkA present in the cornea (Lambiase et al. 2000). KGF is involved in the acceleration of wound healing process by increasing the proliferation of epithelial stem cell in the limbus area and EGF promotes cell migration and proliferation (Sotozono et al. 1995; Wang et al. 2013). All these described properties make the amniotic membrane a very interesting biological tissue for tissue therapy in ophthalmology.

In conventional method for clinical use, the HAM is denuded from its spongy layer and is fractionated in different sample positioned on nitrocellulose membrane and frozen at $-80{ }^{\circ} \mathrm{C}$ until graft. The results of graft are not always constant and in certain patient with severe ocular burns the processes of wound healing are not effectively done in the cornea (Joseph et al. 2001; Clare et al. 2012).

It seems to be important to understand why this heterogeneity occurs in the response to human amniotic membrane graft in certain patient. For in our study we provided a general view of this protein expression in the HAM by making a mapping of these growth factors in order to determine if there were sites to privilege in the whole amnion for graft according to the severity of the ulcer.

In addition to see if there is an intra-donor difference in HAM growths factor expression the variety of protein expression between different placentas was also studied, the intra-donor variation could explain the difference in the processes of wound healing in some patient.

We also were interested in spongy layer; this layer is an intermediate layer between the chorion and the amnion which is removed in the process of preparing the human amniotic membrane patch for grafts (Mamede et al. 2012). It's supposed that this layer can be an important source of growth factors like it's already known for TGF beta (Hopkinson et al. 2006). We think that it seems important to know if by removing the spongy layer we deprive the HAM patch from an important source of growth factor which was beneficial for the process of wound healing in patient's cornea. A number of studies have compared the concentration of growth factor levels between the amnion and the chorion (Koob et al. 2013, 2015; McQuilling et al. 2017). The aim of this study is to compare the superficial layer of the amnion (amnion without the spongy layer) which is grafted in ophthalmology with the spongy layer that is removed in practice. Such a comparison has not been carried out to date.

The result of the mapping of HAM will determine if it is better to kept the spongy layer of the amnion for graft and also to known if a specific zone of the amnion has higher growth factor concentration.

\section{Materials and methods}

Amniotic membrane procurement and handling:

For this study, human placentas were obtained from healthy women, not usable for clinical use, after vaginal delivery $(n=4)$ or caesarean section $(n=2)$ 
after signing the consent form. Local ethics committee approval was obtained, and the study complied with the tenets of the Declaration of Helsinki.

The placentas were handled under laminar flow hood after being treated with antibiotic $(0.2 \mu \mathrm{g} /$ $\mathrm{mL}+$ penicillin and amoxicillin) for $24 \mathrm{~h}$. The placenta is washed with PBS and the chorion layer is separated. Then the amnion is divided in 2 equal parts, one containing its spongy layer and another without its spongy layer (conventional part). Each part is turned over and spread on a stainless steel cup of $200 \mathrm{~mm}$ in diameter and divided in 3 zones depending on the distance from the umbilical cord and 7 patches of 3 $\mathrm{cm}^{2}$ were obtained from each zone. The spongy layer was removed easily with a scraper from the conventional part and kept for protein analysis. The schema of amnion handling is explained in Fig. 1a.

Protein extraction patches were immediately put in precellys lysing tube (Bertin Technologie, France) pre filled with RIPA buffer (Sigma, France) containing protease inhibitor (Thermo fisher, France). They were lysed mechanically using the Precellys lysing Kit (Ozym). The lysis product was transferred into 3 Eppendorf and centrifuged at $16,000 \mathrm{~g}$ for $7 \mathrm{~min} 30$. The supernatant containing proteins was stored at $-80{ }^{\circ} \mathrm{C}$ for analysis.

Enzyme-linked immunosorbent assay (ELISA).

The proteomic analysis done by ELISA targeting growth factors EGF, HGF, KGF, NGF and TGF-b1 and the pro inflammatory cytokine TNF-alpha (Biotechne, R\&D systems, France) using the commercial protocol. Briefly the capture antibody was coated over night at room temperature. The capture antibodies were incubated in blocked solution for $1 \mathrm{~h}$. After that the protein extracted from each patch were incubated 2 $\mathrm{h}$ and the second antibody was added. StreptavidinHRP was added and incubated for $20 \mathrm{~min}$ at room temperature. The result is revealed by adding stabilized hydrogen peroxidase and stabilized tetramethylbenzidine (1/1) and the reaction is stopped with $2 \mathrm{~N}$ sulfuric acid. The optical density is read in $450 \mathrm{~nm}$ by Multiskan FC microplate reader (Thermo Fisher, France).

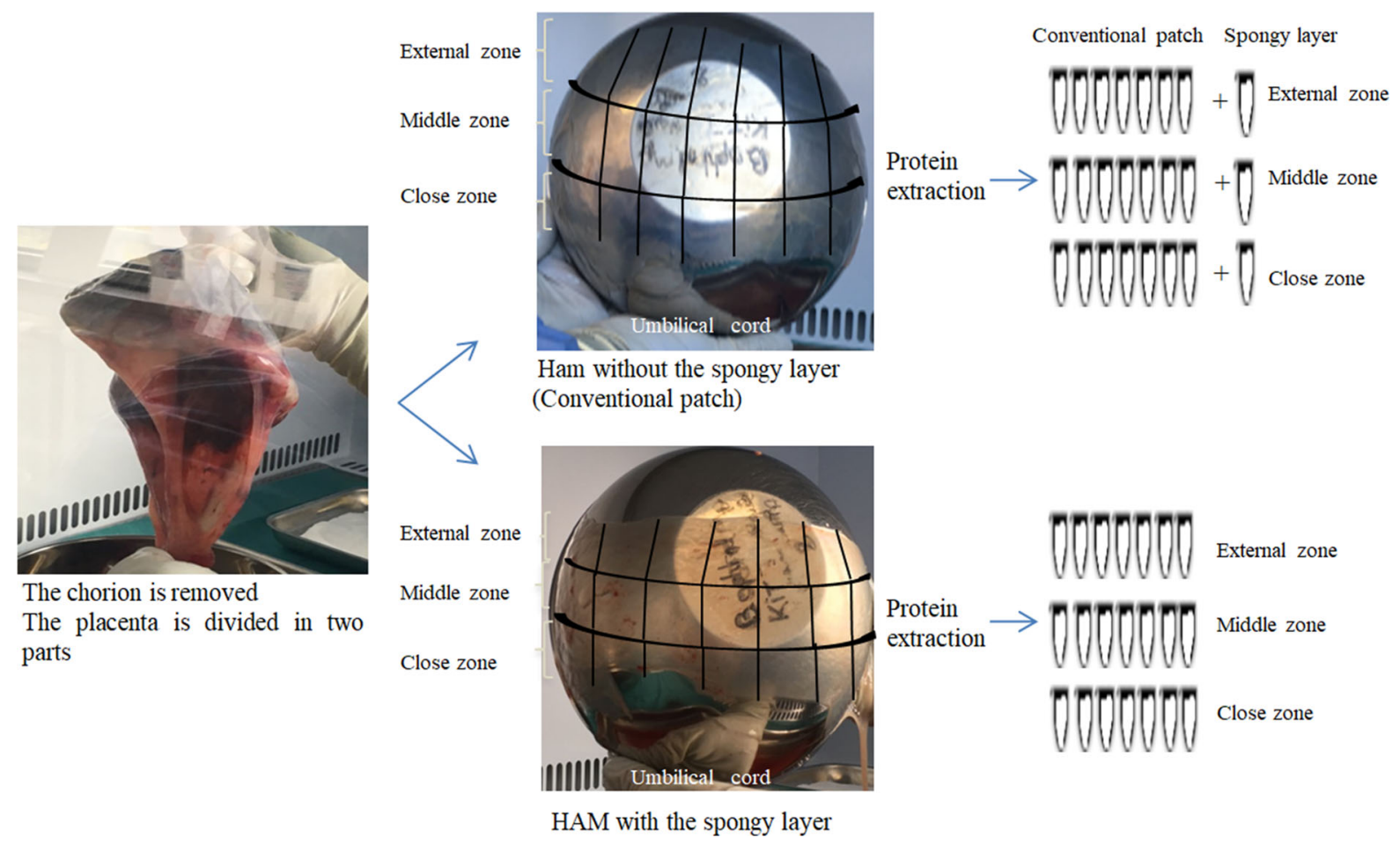

Fig. 1 Schema of amniotic membrane process for protein extraction. To simplify the dissection and have a well spread Amnios, the HAM is turned over and spread on the convexity of a stainless steel cup. We used a stainless steel cup of $200 \mathrm{~mm}$ in diameter. The HAM has been cut in two equal parts and divided in 3 zones depending on the distance from the umbilical cord 
Statistical analysis

Data from different experiments were analyzed using GraphPad Prism ${ }^{\circledR}$ software v.5.00. The statistical tests performed were two-way ANOVA with a Bonferroni post-test. $\quad * p \quad$ value $<0.05, \quad * * p \quad$ value $<0.01$, $* * * \boldsymbol{p}$ value $<0.001$

\section{Results}

Variability of total protein amount in the HAM.

We were interested to know if there is a difference in total protein amount between donors (inter donors difference), and are these differences seen between caesarian and natural birth. The process of HAM handling is schematically represented below (Fig. 1).

The mean of protein extract from the part with the spongy layer, shows a large variation of inter donor's protein amount and not just between caesarean and natural birth (Fig. 2a).

To know further about the eventually interest of keeping the spongy layer, we compare the conventional part (without spongy layer) with its spongy layer. We observed that the spongy layer provided a greater amount of protein; however this difference is statically significant only in HAM5 (Fig. 2b).
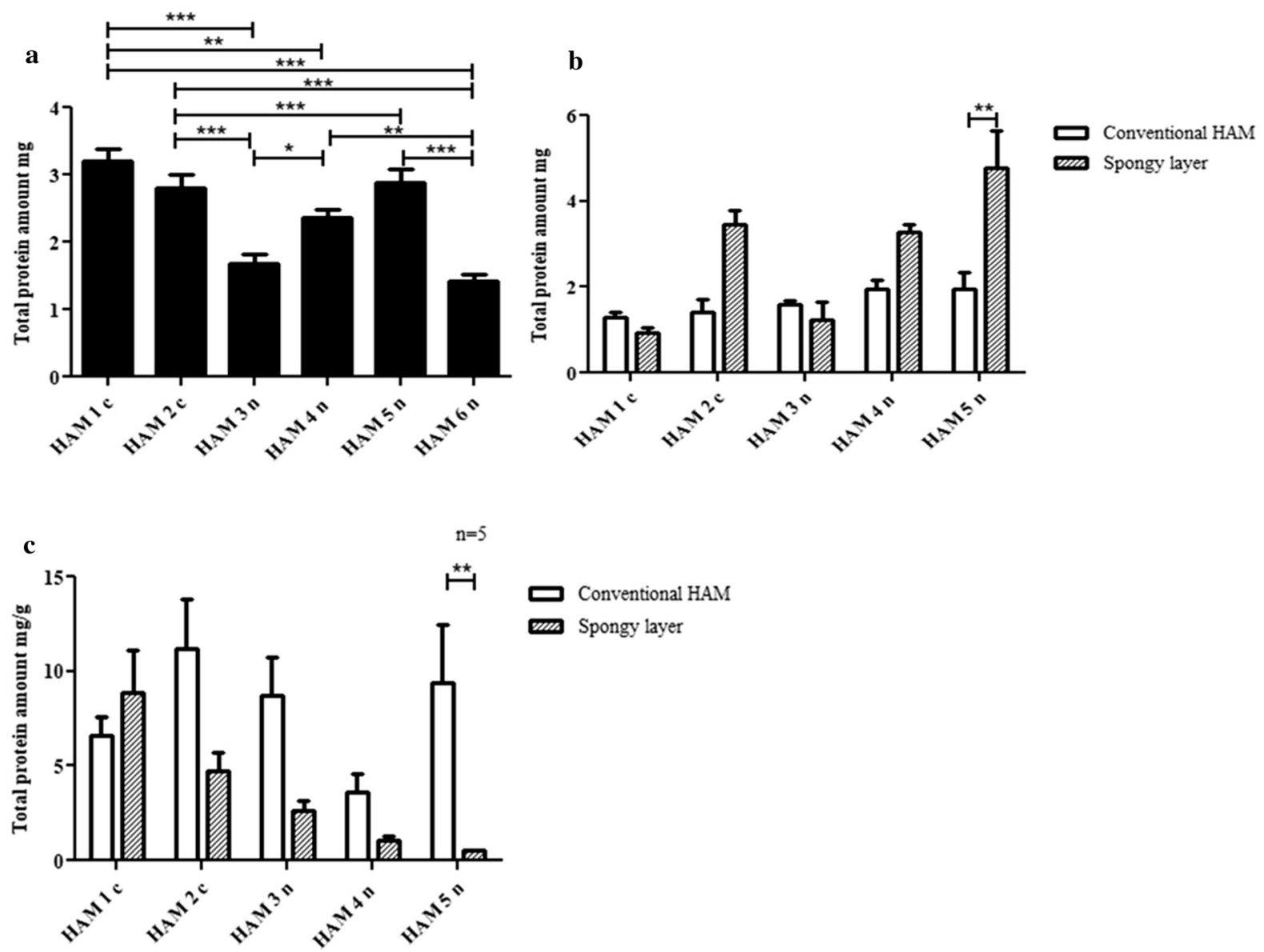

Fig. 2 Total protein amount extracted in Human Amniotique Membrane (HAM). Totale amount of protein in differents HAM $(\mathrm{n}=6$, HAM 1 and 2 from caesarean and HAM 3-6 from natural delivery) (a); Totale protein extracted in conventional HAM (without spongy layer) and its spongy layer ( $\mathrm{n}=5$, HAM 1 and 2 from caesarean and HAM 3-5 from natural delivery) (b); Total amount of protein in different zone of conventional HAM versus spongy layer from thoses zones ( $\mathrm{n}=5$, HAM 1 and 2 from caesarean and HAM 3-5 from natural delivery) (c). The data are present on average \pm SEM, ANOVA statistical test, bonferroni post test, $* p$ value $<0.05$, $* * p$ value $<0.01, * * * p$ value $<0.001$ 

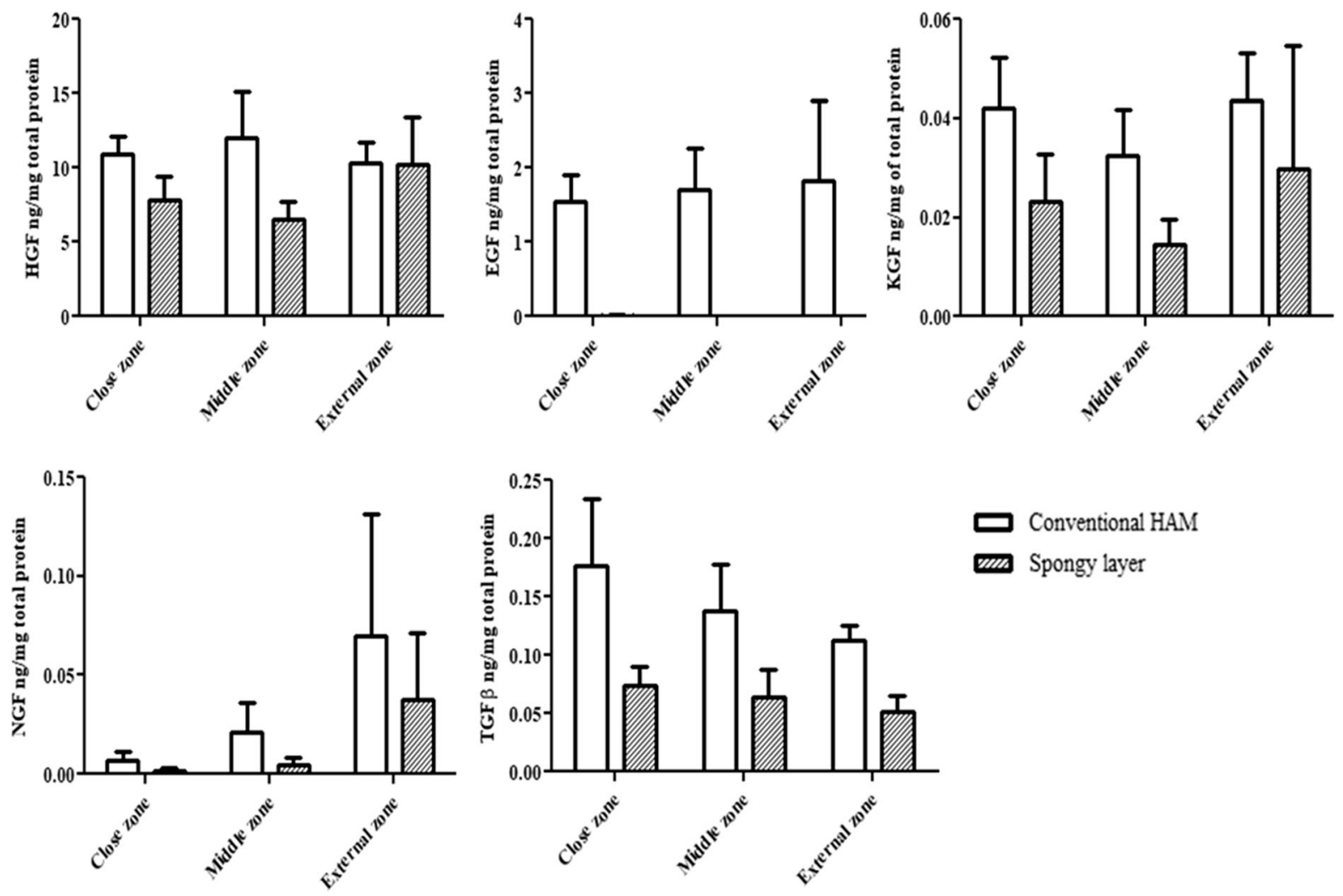

Fig. 3 Growth factor expression in Human Amniotic Membrane (HAM) and spongy layer. Totale amount of growth factor of interest in different zones of HAM $(n=5)$. No difference in the level of growth factors (GF) of interest is seen in HAM and

We also observed this same tendency of the spongy layer to contain more protein, between the different zones in comparison with the protein levels extract from conventional patch in these same zones (Fig. 2c).

Taken together these results showed inter donor difference in total protein extract; the total amount of protein seems to be more important in the spongy layer in one of five amnions.

Thus we investigated whatever the same variation of total protein expression, between different donors and zones of HAM was also observed in the amount of growth factors (GF) that play 4 roles in process of wound healing. Thereafter, in order to realize the mapping of these factors, we studied their expression in the different zone of the HAM and the spongy layer. We observe that there is no significant difference in the amount of GF per mg of total protein in conventional HAM and in the spongy layer and also that there is no spongy layer. No significant difference of GF in different zones is seen. The data are present on average \pm SEM, ANOVA statistical test, bonferroni post test, $* p$ value $<0.05$, $* * p$ value $<0.01, * * * p$ value $<0.001$

difference whether one is in the middle center or the periphery (Fig. 3).

We also do not see a variation of HGF, NGF and TGF beta 1 in the conventional HAM and or spongy layer in different donors (supplementary Fig. 1). The main GF express in the HAM are HGF and EGF, but in the spongy layer no presence of EGF was detected in our study. This result suggests that the spongy layer can bring more GF of interest (excepted EGF) and it would be interesting to keep this layer for faster and better wound healing process.

Effect of proinflammatory cytokine TNF alpha in the rate of HAM growth factors.

In the process of pregnancy the pro-inflammatory cytokines rate changes (Christian and Porter 2014). So we sought to understand if this variation of proinflammatory cytokines had an effect on the rate of 
growth factor in the HAM. This information is helpful in the way that it can guide to detect one parameter that can be chosen to help to select a HAM with more growth factor and so a better and faster wound healing process in severe ulcer.

In our study, we were interested in the proinflammatory cytokine TNF alpha which seems to be express in all placentas (Basu et al. 2016). We analyze if its expression is different in placenta from caesarean (HAM1 and 2) and natural birth (HAM 3-5) (Fig. 4a). We observe a low expression of TNF-alpha in the HAM and there is no difference in its expression in HAM from caesarean and spontaneous delivery. We also do not see any correlation in the amount of TNFalpha present in HAM and the growth factors of interested (Fig. 4b). We conclude that the proinflammatory cytokine TNF-alpha can't be a marker to choose the placenta with more growth factors in it.

Effect of different delivery and mother parameters in the amount of HAM growth factors.

Then we were interested to know if there is any correlation between different donor's parameters and the growth factor of interested. We found a correlation between the KGF and NGF with the time of labor, this correlation seems to be more important with NGF, and no correlation with others GF (Fig. 5). We also do not find any correlation between the donor age, gestational age and the level of HGF, EGF, KGF, NGF and TGF beta (Supplementary Fig. 2). Taken together, these data suggest that the expression of growth factor in placenta is variable and donors dependent.

\section{Discussion}

The graft of human amniotic membrane is a wellknown graft use for wound healing in the cornea. The wound healing process with amniotic membrane graft can take longer in some patients and may give less effective results. This difference in wound healing can be caused by difference of expression of growth factor important in this process due to inter or intra donor variation. For that, in this study, we were investigating if the protein expression in the amniotic membrane is hetero or homogenous. To our knowledge, other studies have compared reflected amnion as a whole
Fig. 4 Effect of TNF alpha on the expression of growth factors implicated in wound healing process. Expression of TNF-alpha in HAM from different donor (HAM 1 and 2 are from cesarean and HAM 3,4,5 from spontaneous delivery) (a); Correlation between TNF alpha and growth factors (b); Inter donors TNF alpha analyze is present on average \pm SEM, ANOVA statistical test, bonferroni post test, ${ }^{*} p$ value $<0.05$, $* * p$ value $<0.01$, $* * * p$ value $<0.001$. Corelation datas are present on Pearson

and did not look at the different regions of the HAM separately (Banerjee et al. 2015, 2018).

We also quantify the growth factor expression in HAM handled conventionally (without spongy layer) and the spongy layer. The importance of protein expression in this layer is not well known. The study of Centurione et al. proposed to evaluate the functionality of reflected amnion in different zones, they compared epithelial cells and their markers in these different zones of the amnion but they did not look at the growth factors expression (Centurione et al. 2018).

In this study, we observed significant difference in the total amount of protein extract between the different donors. We do not observe a significant difference in the growth factors level between the conventional HAM and the spongy layer, this result suggest that the amount of GF in the spongy layer is as important that in conventional HAM. This amount of growth factors in spongy layer can potentially lead to a better wound healing process in patient. Hopkinson et al.2006 had shown that TGF betal is the most isoform of TGF beta family found in human placenta but its rate is less in AM than in the chorion. They also found that there is a variation of TGF beta in different donors. In this study, we choose to measure the TGF beta 1 which is the most isoform expressed in placentas as said above. In our founding the expression of TGF beta 1 is not significantly different in conventional HAM and the spongy layer. So in the process of handling the removal of the TGF beta 1 present in this layer may have no effect in the wound healing process.

The amount of TGF beta 1 found in our study was low, the low amount of TGF beta is beneficial because of its simulative affected on expression of some MMP by human corneal epithelial (Kim et al. 2004), but its presence is also important because of its role in regulation of tight junction protein expression and distribution (Contreras-Ruiz et al. 2012). 

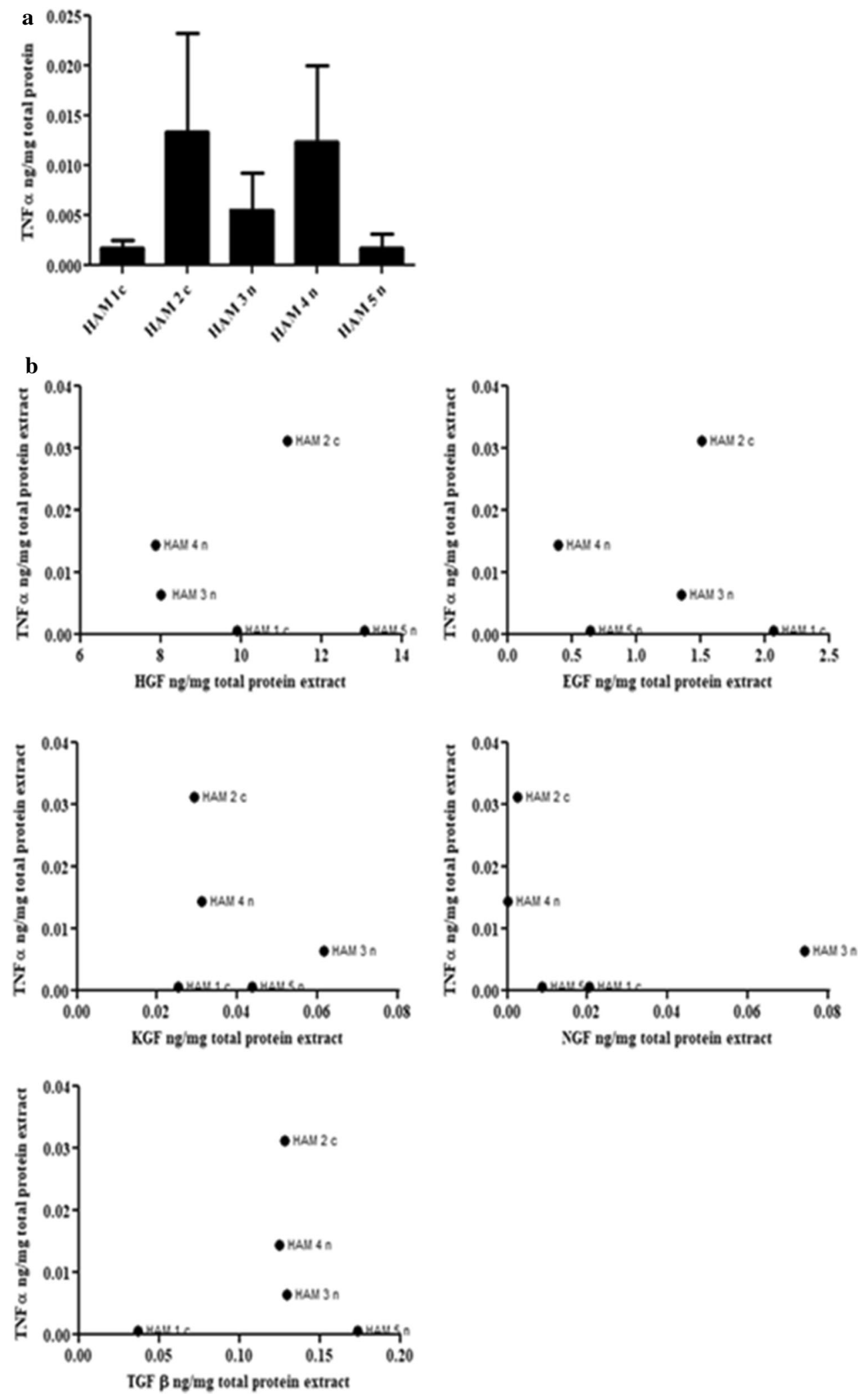

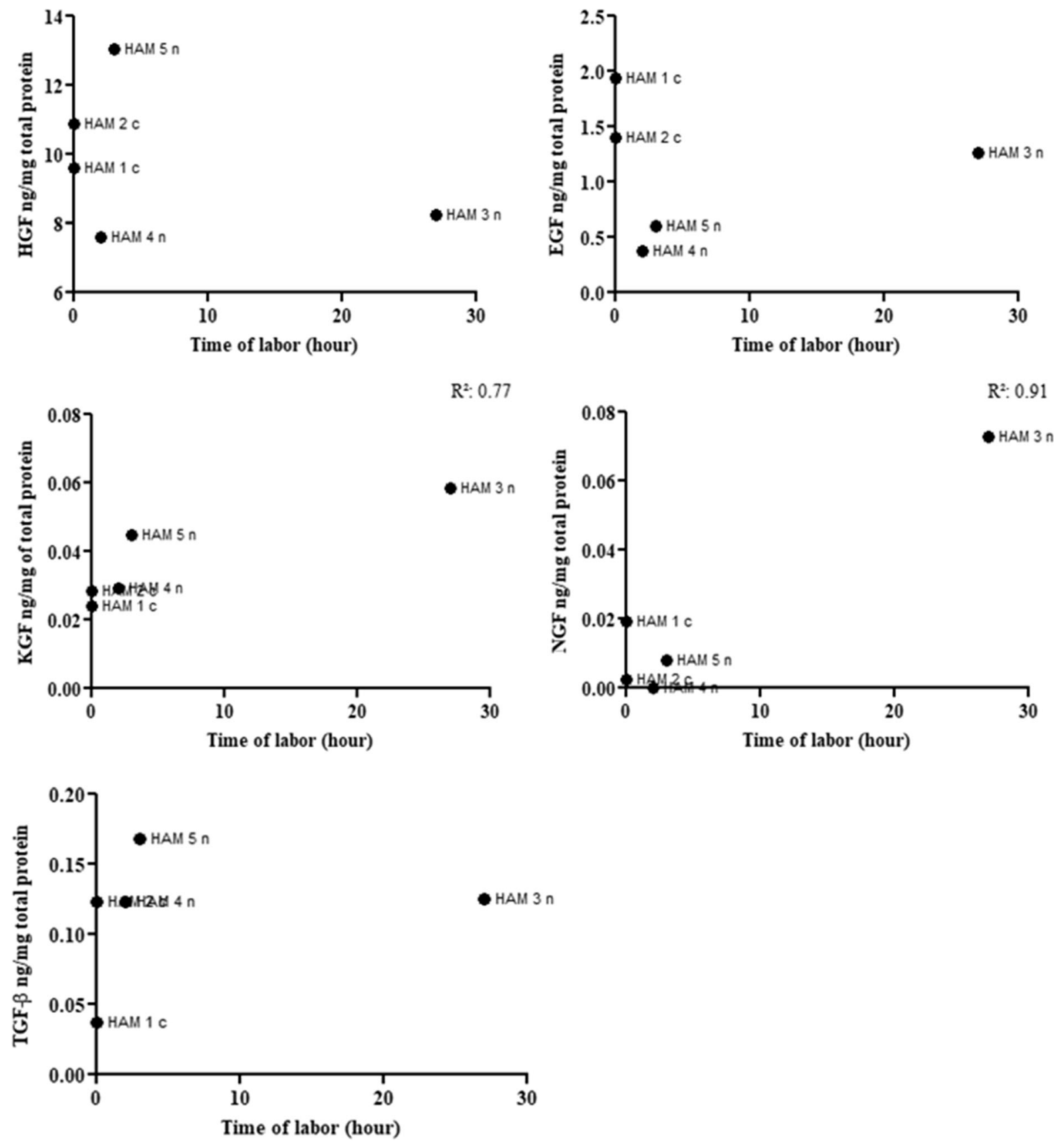

Fig. 5 Correlation between time of labor and growth factors. The time of labor is demontrated by hour. For caesarean the time of labor is equal 0 ( $n=5$ placentas). Corelationdatas are present on Pearson

We do not observe the expression of EGF in the spongy layer, it is also interesting that the EGF is more expressed in the amnion than the chorion layer of the placenta (Go et al. 2016). Gicquel et al. shows the inter donor variation of EGF and its variation of expression in different zone of placenta (Gicquel et al. 2009). In our results we also observe the inter donor variation, but we do not find a significant difference in expression of growth factor in different zone of HAM.

No variation was observed in the expression of HGF, KGF and NGF in different zone of HAM and 
neither between conventional HAM and spongy layer in each zone.

Mitchell et al. 1990 have demonstrated that release of TNF-alpha can stimulate the production of prostaglandin in placenta, in our study we verified if this cytokine can have an effect in the growth factors of interest but the result does not show a correlation in their expression (Mitchell et al. 1990). Lopez et al. show that the gestational age and the donor age influence the growth factor levels (López-Valladares et al. 2010). In our study we also looked at different parameters, time of labor, gestational age, age and number of births that can play on all these GF in order to find a criterion of HAM selection that will be richer in growth factors. We have not seen a correlation between these different parameters and the level of GF expression.

In conclusion, in our study we demonstrated that keeping the spongy layer in conventional method of handling HAM can add more GF, and so probably have a positive affect the wound healing process. Variation in some growth factors expression has been observed between the placentas and therefore this may explain the variation in clinical results. No indicator for the selection of placentas with a higher rate of growth factor was found.

This article does not contain any studies with animals performed by any of the authors.

Acknowledgements Thanks to Charlotte QUETTEVILLE for the help she has provided in recruiting placentas.

Funding This works was co-supported by European Union and Normandie Regional Council. Europe gets involved in Normandie with European Regional Development Fund (ERDF), (17B07001E).

\section{Compliance with Ethical Standards}

Conflict of interest The authors do not have any conflict of interest.

Ethical approval All procedures performed in this study were in accordance whit the ethical standard of French bioethics laws ( $\left.{ }^{\circ} \mathrm{AC}-2013-1886\right)$, and the study complied with the tenets of the Declaration of Helsinki 1964 and its later amendments or comparable ethical standards.

Informed consent Informed consent was obtained from all individual participants included in this study.

\section{References}

Banerjee A, Weidinger A, Hofer M et al (2015) Different metabolic activity in placental and reflected regions of the human amniotic membrane. Placenta 36:1329-1332

Banerjee A, Lindenmair A, Hennerbichler S et al (2018) Cellular and site-specific mitochondrial characterization of vital human amniotic membrane. Cell Transpl 27:3-11

Basu J, Agamasu E, Bendek B et al (2016) Placental tumor necrosis factor- $\alpha$ protein expression during normal human gestation. J Matern Fetal Neonatal Med 29:3934-3938

Centurione L, Passaretta F, Centurione MA et al (2018) Mapping of the human placenta. Cell Transpl 27:12-22

Christian LM, Porter K (2014) Longitudinal changes in serum proinflammatory markers across pregnancy and postpartum: effects of maternal body mass index. Cytokine 70:134-140

Clare G, Suleman H, Bunce C, Dua H (2012) Amniotic membrane transplantation for acute ocular burns. Cochrane Datab System Rev. https://doi.org/10.1002/14651858. CD009379.pub2

Contreras-Ruiz L, Schulze U, García-Posadas L et al (2012) Structural and functional alteration of corneal epithelial barrier under inflammatory conditions. Curr Eye Res 37:971-981

Rötth A de (1940) Plastic repair of conjunctival defects with fetal membranes. Arch Ophthalmol 23:522-525

Gicquel J-J, Dua HS, Brodie A et al (2009) Epidermal growth factor variations in amniotic membrane used for Ex Vivo tissue constructs. Tissue Eng Part A 15:1919-1927

Go YY, Kim SE, Cho GJ et al (2016) Promotion of osteogenic differentiation by amnion/chorion membrane extracts. J Appl Biomater Funct Mater 14:171-180

Hao Y, Ma DH, Hwang DG et al (2000) Identification of antiangiogenic and antiinflammatory proteins in human amniotic membrane. Cornea 19:348-352

Hopkinson A, McIntosh RS, Tighe PJ et al (2006) Amniotic membrane for ocular surface reconstruction: donor variations and the effect of handling on TGF- $\beta$ content. Invest Ophthalmol Vis Sci 47:4316-4322

Joseph A, Dua HS, King AJ (2001) Failure of amniotic membrane transplantation in the treatment of acute ocular burns. Br J Ophthalmol 85:1065-1069

Kim JC, Tseng SC (1995) Transplantation of preserved human amniotic membrane for surface reconstruction in severely damaged rabbit corneas. Cornea 14:473-484

Kim H-S, Shang T, Chen Z et al (2004) TGF- $\beta 1$ stimulates production of gelatinase (MMP-9), collagenases (MMP-1, -13) and stromelysins (MMP-3, -10, -11) by human corneal epithelial cells. Exp Eye Res 79:263-274

Koizumi NJ, Inatomi TJ, Sotozono CJ et al (2000) Growth factor mRNA and protein in preserved human amniotic membrane. Curr Eye Res 20:173-177

Koob TJ, Rennert R, Zabek N et al (2013) Biological properties of dehydrated human amnion/chorion composite graft: implications for chronic wound healing. Int Wound J 10:493-500

Koob TJ, Lim JJ, Zabek N, Massee M (2015) Cytokines in single layer amnion allografts compared to multilayer 
amnion/chorion allografts for wound healing. J Biomed Mater Res Part B Appl Biomater 103:1133-1140

Lambiase A, Bonini S, Aloe L et al (2000) Anti-inflammatory and healing properties of nerve growth factor in immune corneal ulcers with stromal melting. Arch Ophthalmol 118:1446-1449

López-Valladares MJ, Rodríguez-Ares MT, Touriño R et al (2010) Donor age and gestational age influence on growth factor levels in human amniotic membrane. Acta Ophthalmol 88:e211-e216

Malak TM, Ockleford CD, Bell SC et al (1993) Confocal immunofluorescence localization of collagen types I, III, IV, V and VI and their ultrastructural organization in term human fetal membranes. Placenta 14:385-406

Mamede AC, Carvalho MJ, Abrantes AM et al (2012) Amniotic membrane: from structure and functions to clinical applications. Cell Tissue Res 349:447-458

McQuilling JP, Vines JB, Kimmerling KA, Mowry KC (2017) Proteomic comparison of amnion and chorion and evaluation of the effects of processing on placental membranes. Wounds 29:E38-E42

Mitchell MD, Edwin S, Romero RJ (1990) Prostaglandin biosynthesis by human decidual cells: effects of inflammatory mediators. Prostaglandins Leukot Essent Fatty Acids 41:35-38

Miyagi H, Thomasy SM, Russell P, Murphy CJ (2018) The role of hepatocyte growth factor in corneal wound healing. Exp Eye Res 166:49-55

Parry S, Strauss JF (1998) Premature rupture of the fetal membranes. N Engl J Med 338:663-670

Pierucci-Alves F, Yi S, Schultz BD (2012) Transforming growth factor beta 1 induces tight junction disruptions and loss of transepithelial resistance across porcine vas deferens epithelial cells. Biol Reprod 86:36

Schmidt W (1992) The amniotic fluid compartment: the fetal habitat. Adv Anat Embryol Cell Biol 127:1-100

Sotozono C, Inatomi T, Nakamura M, Kinoshita S (1995) Keratinocyte growth factor accelerates corneal epithelial wound healing in vivo. Invest Ophthalmol Vis Sci 36:1524-1529

Wang L, Wu X, Shi T, Lu L (2013) Epidermal growth factor (EGF)-induced corneal epithelial wound healing through nuclear factor $\kappa \mathrm{B}$ subtype-regulated CCCTC binding factor (CTCF) activation. J Biol Chem 288:24363-24371 